\title{
Prospective randomized comparison between laparoscopic and conventional hernioplasty in the treatment of ventral abdominal hernias
}

\author{
Ibrahim H. Othman, MD; Ashraf A. Alattar, MD; Mohamed A. Hablus, MD; \\ H. M Abdelhady, MD; Taha A. Ismail, MD
}

Department of General Surgery, Faculty of Medicine, Tanta University, Egypt.

Objectives: This randomized prospective study compares the effectiveness of laparoscopic ventral hernioplasty to the conventional open hernioplasty.

Patients and methods: Forty patients with ventral hernias were randomized into 2 equal groups. Group L treated by laparoscopic hernioplasty and Group O treated by open hernioplasty. Patients were followed for $35.5 \pm 15.3$ months in Group L patients and $32.5 \pm 14.5$ months in Group O patients.

Results: Mean greater dimension of hernia defect was $6.40 \pm 2.76 \mathrm{~cm}$ in group L and 5.25 $\pm 2.94 \mathrm{cms}$ in Group $O$ (p: 0.21). In group L, mean operative time was $59.4 \pm 16.4$ minutes. In group $O$ it was $47.2 \pm 13.8$ minutes ( $p$ : 0.016). Postoperative pain score 6 hours after surgery was $2.95 \pm 1.19$ in group L patients versus $3.75 \pm 0.786$ in group O patients (p: 0.017 ). Group $L$ patients needed a mean of $1.20 \pm 0.410$ ampoules of $100 \mathrm{mg}$ Pethedine for analgesia in the first postoperative day versus $2.15 \pm 0.671$ ampoules in group O patients $(p<0.0001)$. Mean hospitalization time was $1.10 \pm 0.308$ days in group $L$ versus $1.45 \pm 0.605$ days in group $O$ (p: 0.027). We had 1 conversion (2.5\%) to the open repair. Postoperative seroma occurred in 2 patients (5\%) in group $L$ and 2 patients (5\%) in group O. Two patients (5\%) in group $O$ developed surgical site infection. Hernia recurrence was not seen in either Group. Mean patient satisfaction score for Group L patients was $7.90 \pm 1.25$ versus $6.00 \pm 1.72$ for Group O patients (p: 0.0003).

Conclusion: Compared to open repair, laparoscopic repair is technically feasible, safe and effective, with good clinical outcome. It is associated with longer time for surgery but reduced post-operative pain, analgesic requirement, complication rate and infection rate and earlier return to normal activities.

Key words: Laparoscopic, conventional, ventral hernioplasty.

\section{Introduction:}

The common ventral abdominal hernias include paraumbilical, incisional, umbilical, and epigastric hernias. Primary ventral hernias occur spontaneously due to primary fascial pathology. ${ }^{1}$ Postoperative ventral hernia or incisional hernia is a common complication following abdominal surgery and is a significant cause of morbidity. ${ }^{2}$ Incisional hernia develops in $3-13 \%$ of laparotomy incisions. ${ }^{3}$

All varieties of ventral hernias are characterized by a defect in the anterior abdominal wall. The optimum treatment for such hernias is still under debate and there are no guidelines as to the most appropriate treatment. ${ }^{4}$

Tension-free repair is one of the key concepts in hernia surgery resulting in decrease in recurrence rate. The laparoscopic approach for repair of ventral hernias was first reported in the early 1990s. Since that time, the technique has evolved into an accepted repair for the management of ventral hernias. 
The many reports of excellent clinical results have made laparoscopic ventral hernia repair one of the fastest growing minimally invasive techniques of the past several years as it combines the benefits of minimal recurrence and minimal wound complications. ${ }^{5}$

Laparoscopic repair of ventral hernias is rapidly becoming more common, its utility, cost-effectiveness, lower infection and recurrence rates make it very attractive. ${ }^{6}$

This randomized prospective study was designed to compare the effectiveness of laparoscopic ventral hernioplasty to the conventional open technique.

\section{Patients and methods:}

This study was performed in General Surgery Department, Tanta University Hospitals, Egypt during the period from March 2006 to December 2011 on 40 patients with ventral hernia. Full explanation of procedures; possible complications and patient consent were assured before inclusion in the research. The study protocol was approved by the Ethics Committee of General Surgery Department, Tanta University Hospitals.

Patients were randomly categorized into 2 groups through a computer randomization program. Group L included 20 patients operated on by laparoscopic ventral hernioplasty. This group was compared to 20 patients undergoing conventional (open) ventral hernioplasty (Group $\mathrm{O}$ ).

All patients underwent detailed medical history, clinical examination and abdominal ultrasound examination in addition to routine hematological and biochemical investigations for preparation for general anesthesia.

Patients were hospitalized on the day of surgery. All procedures were performed under general anesthesia. All patients received a single dose of intravenous Augmentin 1.2 grams 30 minutes prior to surgery.

Patients in group L underwent laparoscopic ventral hernioplasty. An angled (30 degrees) $10 \mathrm{~mm}$ telescope was used in all cases. All patients were catheterized to decompress the urinary bladder. Gastric decompression was achieved by placement of a naso-gastric tube.
The patients were placed in a supine position. Access to the abdomen was accomplished by means of either the open technique or Veress needle in left upper quadrant except after splenectomy and left colon surgery or other left upper abdominal surgery.

A $10 \mathrm{~mm}$ trocar was passed into the abdomen, located midway between left costal margin and left iliac crest along the anterior axillary line; another three $5 \mathrm{~mm}$ trocars were passed into the abdomen, one located at the left lower quadrant in the midclavicular line below the level of the umbilicus, the other 2 were located in the right lower quadrant; one in the midclavicular line and one along the anterior axillary line below the level of the umbilicus.

Adhesiolysis and taking down of adherent omentum were done using sharp dissection with minimal use of diathermy to avoid inadvertent thermal injury to the bowel. The hernia contents were reduced but the peritoneal sac was left in-situ. The margins of the hernia defect were delineated and measured. four-layer composite mesh (PROCEED ${ }^{\mathrm{TM}}$ Mesh by Ethicon, Johnson \& Johnson Company) was used.

The mesh was tailored $3 \mathrm{~cm}$ larger than the defect from all margins. In early cases the mesh was fixed by sutures secured at the 4 corners of the mesh passing through the anterior abdominal wall from the telescope port and picked to the outside using suture passer and tied on the outer surface of abdominal wall over a piece of gauze and were cut at the skin level after 2 weeks. In the latter cases the 4 corners of the mesh were fixed from inside using 3/0 polypropylene stitches not reaching to the skin. The circumference of the mesh was then tacked at intervals of $1 \mathrm{~cm}$ forming double crown. No drains were inserted.

For group $\mathrm{O}$ patients, the operation was done in supine position. A transverse skin incision was done over the hernia. Dissection of the sac, opening it, reduction of the contents, and excision of sac was done with closure of the peritoneum. Polypropylene mesh was inserted as a sublay repair under the defect in the preperitoneal space either immediately over the closed peritoneum or 
over a closed fascial layer after component separation.

In both situations the mesh was fixed and spread in the preperitoneal space by 3/0 polypropylene corner stitches tied over the fascial layer after closure of the defect. Closure of the defect was done using 1 polypropylene stitches. Skin was closed with suction drainage.

Patients were allowed to drink 3 hours after recovery. Analgesia was given in the form of $100 \mathrm{mg}$ Pethedine on recovery and another $100 \mathrm{mg}$ Pethedine intramuscularly after 12 hours if the patient complains of pain. Postoperative pain was measured 6 hours after surgery using pain visual analog scale.

Patients were discharged from hospital in the first post-operative morning in most cases. Patient satisfaction score was designed by asking patients to express their satisfaction in a numerical score from 0 to 10 one month after surgery.

Patients were followed in visits at three day interval for two weeks then every 3 months. Patients that did not come for follow up were contacted by telephone. Patients were encouraged to visit the clinic at any time if they have any problem. The mean length of follow up was $35.5 \pm 15.3$ months in Group L patients and $32.5 \pm 14.5$ months in Group O patients.

Statistical analysis: Quantitative variables were expressed as mean \pm SD. Qualitative variables were expressed as frequency and percent. Quantitative parametric variables were compared between the two groups using the unpaired student t-test, quantitative nonparametric variables were compared using Mann-Whitney test. Qualitative variables were compared using Chi-square test or Fisher exact test when the criteria for using Chi-square were not sufficient. The power used was 0.80 while the level of significance was $5 \%$.

\section{Results:}

The demographic characteristics of patients studied, types of hernia and size of hernia defect were summarized in Tables(1- 3).

Operation time: In group L, operative time ranged from 40-95 minutes (mean operative time: $59.4 \pm 16.4$ minutes). In group $\mathrm{O}$, operative time ranged from 35-90 minutes (mean operative time: $47.2 \pm 13.8$ minutes). The difference between the two groups was statistically significant (p: 0.016).

Postoperative pain: Postoperative pain score measured 6 hours after surgery was $2.95 \pm 1.19$ in group $L$ patients versus 3.75 \pm 0.786 in group $\mathrm{O}$ patients (p: 0.015$)$. Group $\mathrm{L}$ patients needed a mean of $1.20 \pm 0.410$ ampoules of $100 \mathrm{mg}$ Pethedine for analgesia in the first postoperative day. Group $\mathrm{O}$ patients needed a mean of $2.15 \pm 0.671$ ampoules of $100 \mathrm{mg}$ Pethedine for analgesia in the first postoperative day $(\mathrm{p}<0.001)$.

Hospitalization time: Hospitalization time ranged from 1-2 days in both groups. Mean hospitalization time was $1.10 \pm 0.308$ days in group $\mathrm{L}$. In group $\mathrm{O}$, mean hospitalization time was $1.45 \pm 0.605$ days. The difference between the two groups was statistically significant (p: 0.026).

Time to return to normal activity: Time to return to normal activity ranged from 4-8 days in group $\mathrm{L}$ (mean time: $5.65 \pm 0.988$ days). In group $\mathrm{O}$, time to return to normal activity ranged from 6-27 days (mean time: $14.4 \pm 4.90$ days). The difference between the two groups was statistically significant $(\mathrm{p}<0.001)$.

Complications: We had to convert 1 patient (2.5\%) to the open repair due to lack of experience at the start of our research. postoperative seroma occurred in 2 patients (5\%) in group L and 2 patients (5\%) in group O. All patients were successfully treated conservatively. Two patients (5\%) in group O developed surgical site infection. They were managed by proper antibiotic according to culture and sensitivity result. Hernia recurrence was not seen in either 2 Groups. The difference between the complication rates in two groups was statistically insignificant (p: 0.661). Post-operative complications are summarized in Table(4).

Patient satisfaction: The mean patient satisfaction score for Group L patients was $=7.90 \pm 1.25$ versus $6.00 \pm 1.72$ for Group $\mathrm{O}$ patients. The difference between the two 
groups was statistically significant ( $\mathrm{p}: 0.049)$.

\section{Discussion:}

A lasting surgical correction of a ventral hernia remains a challenge. Open primary suture repair has led to extremely high recurrence rates. For a fascial defect equal to or more than $4 \mathrm{~cm}$ in size, the recurrence rate exceeds $40 \%$. For a fascial defect less than $4 \mathrm{~cm}$ in size, the recurrence rate can be as high as $25 \%{ }^{7}$

The use of prosthetic mesh came to popularity after it was shown that the longterm failure rate could be reduced to $11 \%{ }^{7}$ However, the placement of mesh typically required extensive soft tissue dissection, raising of flaps and insertion of drains, increasing the incidence of wound infection and local wound complications. ${ }^{8-10}$

The laparoscopic repair of ventral hernia utilizes the principles of the open technique popularized by Stoppa, Rives et al. and Wantz. ${ }^{11-13}$ These principles include using large mesh prosthesis, adequate overlap of the hernia defect, and eliminating tension. In the laparoscopic technique, the mesh is placed intraperitoneally and extensive soft tissue dissection is eliminated.

Intraperitoneal placement of mesh without sac excision seems to be the near-universal method of mesh positioning. ${ }^{14}$

All of the hernias in our series were repaired with four-layer composite mesh (PROCEED ${ }^{\mathrm{TM}}$ Mesh by Ethicon, Johnson \& Johnson Company). The polypropylene mesh side of the product allows for tissue ingrowth while the ORC (oxidized regenerated cellulose) side provides a bioresorbable layer that physically separates the polypropylene mesh from underlying tissue and organ surfaces during the wound-healing period to minimize intestinal attachment to the mesh. $9,15,16$

The ORC side appears to be less easily infected than other biomaterials. ${ }^{17}$ It is therefore recommended that mesh materials be separated from the intestine, whenever possible. ${ }^{18-20}$ For this purpose, the PROCEED ${ }^{\mathrm{TM}}$ Mesh is well suited.

Intra-abdominal placement of a large mesh with wide overlap of defects, use of smaller incisions, laparoscopic adhesiolysis to uncover small unpalpable defects that may go unnoticed with open repair, and use of large non-absorbable sutures for stronger patch fixation could account for the greater success of the laparoscopic operation. ${ }^{21}$

It has been shown that with laparoscopic repair of ventral hernia wound complication rate, patient discomfort, length of hospital stay, time to return to normal activities and recurrence rates are all reduced.22,23 Laparoscopic repair of ventral hernia has also been established as a cost-effective procedure, with total facility costs for the laparoscopic repair being significantly lower than that for the open repair. ${ }^{24}$

The major complications following laparoscopic repair of ventral hernia are well documented. These include enterotomy, mesh infection, skin breakdown, intraabdominal abscess and mortality. The overall complication rates range from $0 \%$ to $24 \% .^{25}$ There were no operative mortalities or major complications in our series.

It has been observed that seroma at the site of hernia repair and suture site pain were the most common minor complications reported1.5,20,26

Seroma is defined as any bulge at the operation site observed by the surgeon or the patient. It is considered significant if it lasts more than six weeks. We found that all of them resolved without treatment within six weeks. Heniford et al., recommended aspirating seromas in patients who are symptomatic, and allowing the others to resolve spontaneously. ${ }^{27}$

The suture site pain experienced may originate from tissue or nerve entrapment during placement of sutures or tacks through the full thickness of the anterior abdominal wall. It could result from traction of the transabdominal sutures fixing the mesh to the anterior abdominal wall. However, suture placement is vital to the long-term durability of the mesh repair and we do not advocate any change in the technique. Suture site pain can be managed conservatively. In our series suture site pain was not realized because we 


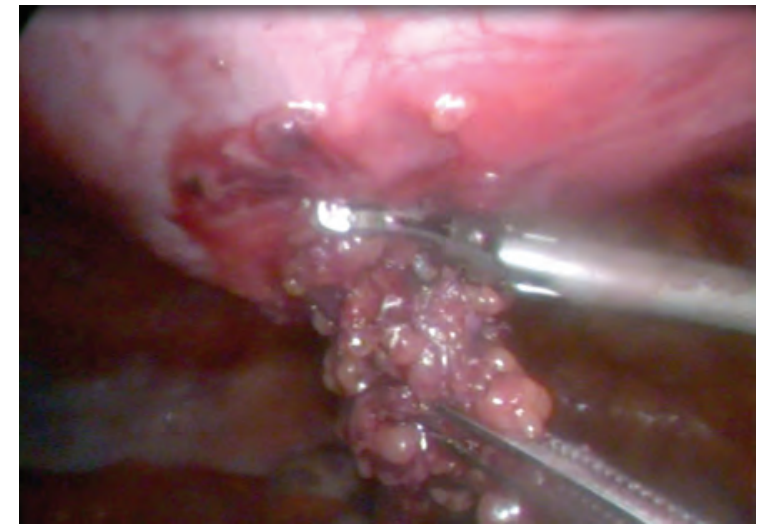

Figure (1): Reduction of the hernia content by adhesiolysis using harmonic scalpel.

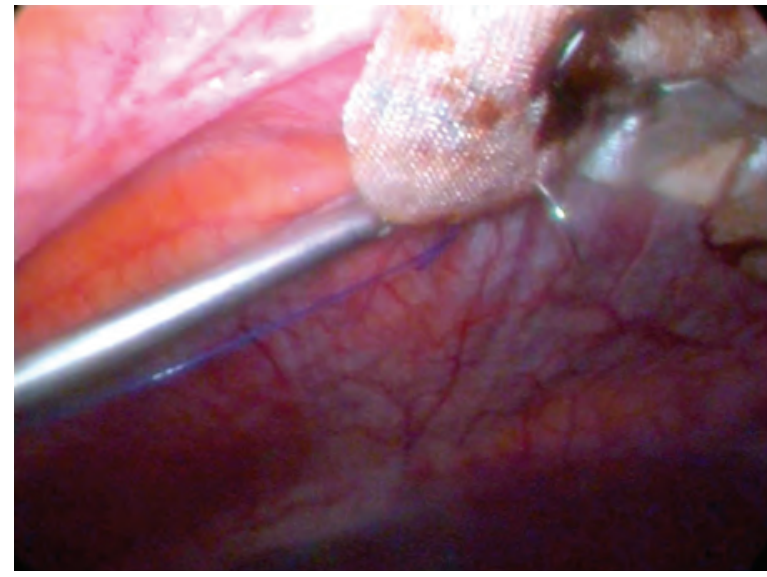

Figure (3): Fixation of the mesh from inside using 3/0 polypropylene stitches not reaching to the skin at the four corners.

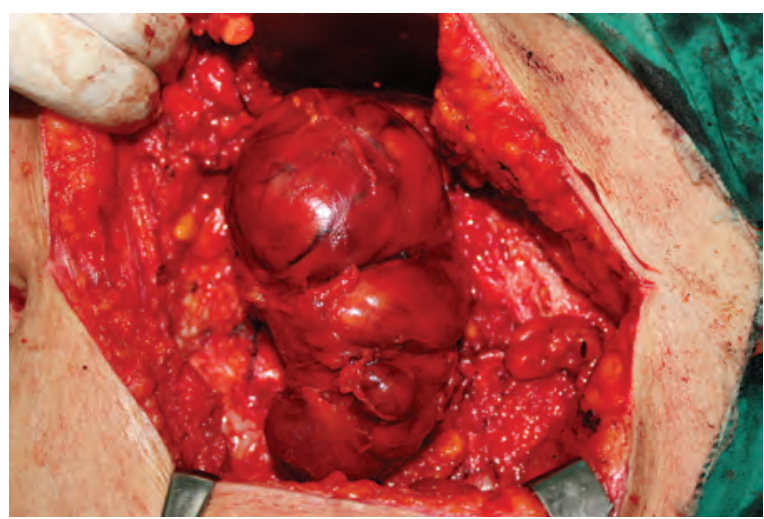

Figure (5): Incisional hernia before opening the hernial sac. .

used a single suture in every corner fixed from inside and not reaching to the skin.

The recurrence rate in our series was $0 \%$, Recurrence rates following laparoscopic

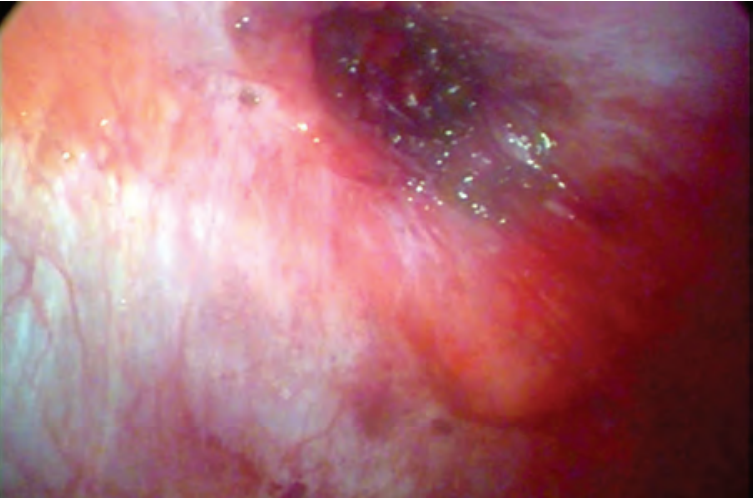

Figure (2): The hernial defect after reduction of the content.

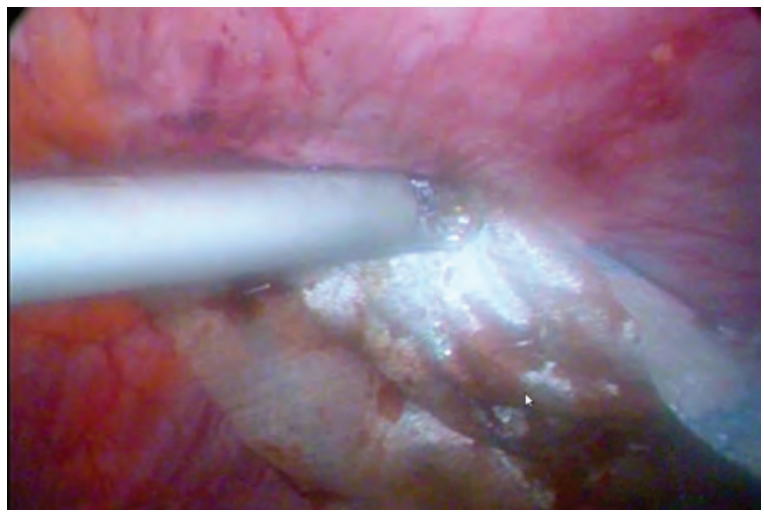

Figure (4): Spreading of the folded mesh over the defect with stapler fixation of the mesh .

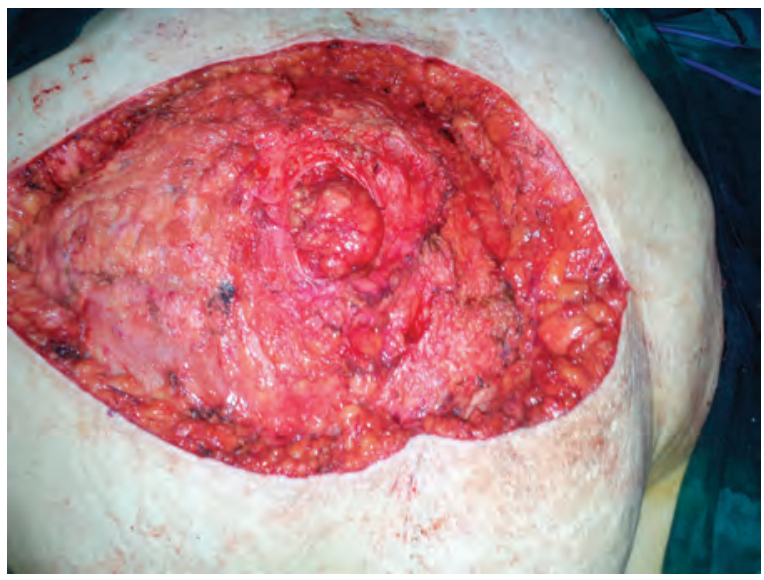

Figure (6): The hernial defect after reduction of the contents and excision of the hernial sac and closure of the peritoneum. .

repair in other 60 series averaged $3.61 \%$ repair in the meta analysis of Carlson et al., ${ }^{14}$ Table(3).

Sauerland et al., ${ }^{28}$ compared laparoscopic 


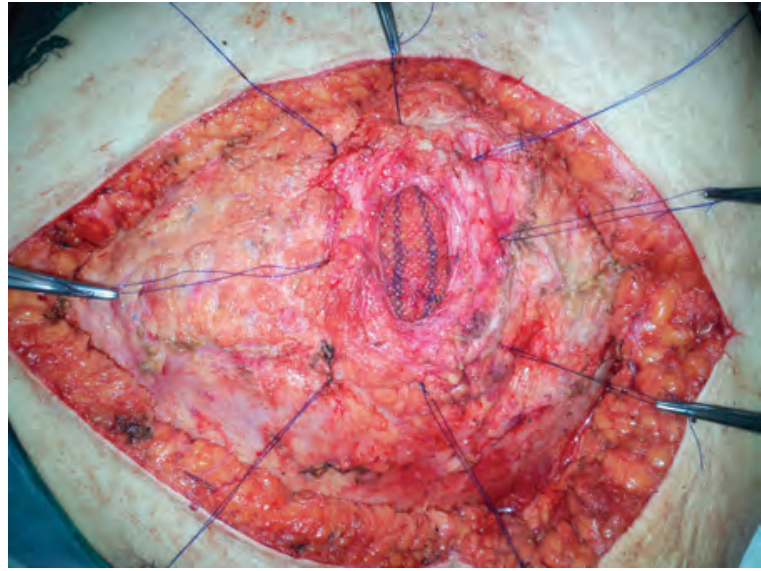

Figure (7): Spreading of the mesh in the preperitoneal space by corner stitches (clock face technique) tied over the aponeurotic layer after closure of the defect.

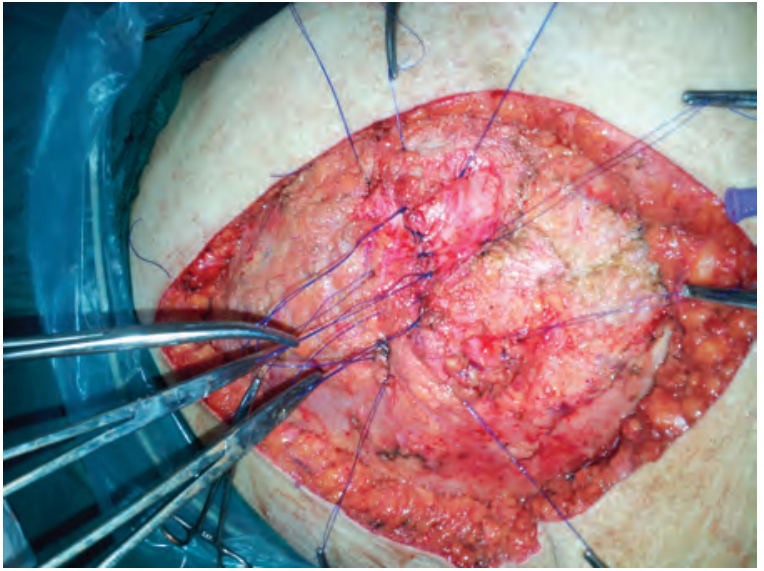

Figure (8): Closure of the hernial defect using interrupted polypropylene stitches.

Table (1): The demographic characteristics of patients.

\begin{tabular}{|l|l|l|l|}
\hline & Group L & Group O & p. value \\
\hline Age & $36.5 \pm 8.76$ & $42.5 \pm 11.9$ & 0.092 \\
\hline Gender & 15 & 13 & \\
Females & 5 & 7 & 0.490 \\
Males & & & \\
\hline Occupation & 8 & 8 & \\
Housewives & 6 & 9 & 0.726 \\
Manual worker & 4 & 3 & \\
Intellectual worker & & & \\
\hline Complaints & 20 & 20 & 0.979 \\
Swelling & 8 & 9 & \\
Pain & 2 & 2 & \\
Dyspepsia & $30.9 \pm 3.96$ & $31.6 \pm 4.77$ & 0.634 \\
\hline Mean body mass index & \multicolumn{2}{|}{} \\
\hline
\end{tabular}

Table (2): Types of hernia.

\begin{tabular}{|l|l|l|l|}
\hline Type of hernia & Group L & Group O & p. value \\
\hline Umbilical & 7 & 8 & 0.763 \\
\hline Epigastric & 2 & 2 & 1.00 \\
\hline Incisional & 11 & 10 & \\
- Upper midline & 5 & 3 & \\
- Lower midline & 3 & 4 & 0.963 \\
- Pfannenstiel & 2 & 2 & \\
- Grid iron & 1 & 1 & \\
\hline
\end{tabular}


Table (3): Greater dimension of hernia defect.

\begin{tabular}{|l|l|l|l|}
\hline Greater dimension of defect & Group L & Group O & \multirow{2}{*}{ p. value } \\
\hline $2-5 \mathrm{~cm}$ & 10 & 13 & \multirow{2}{*}{0.603} \\
\cline { 1 - 3 } $6-10$ & 8 & 6 & \\
\hline$>10$ & 2 & 1 & \multirow{2}{*}{0.143} \\
\hline
\end{tabular}

The difference in mean greater dimension of hernia defect is statistically insignificant (p: 0.143).

Table (4): Postoperative complications in both groups.

\begin{tabular}{|l|l|l|}
\hline Post operative complication & Number & Percentage \\
\hline Group L & & \\
Conversion to open procedure & 1 & $2.50 \%$ \\
Seroma & 2 & $5.00 \%$ \\
\hline Group O & & \\
Seroma & 2 & $5.00 \%$ \\
Superficial wound infection & 1 & $2.50 \%$ \\
Deep infection & 1 & $2.50 \%$ \\
\hline
\end{tabular}

Table (5): Summary of major outcome data of laparoscopic ventral hernia repair in the metaanalysis of Carlson et al.,(14).

\begin{tabular}{|l|l|l|l|l|l|l|}
\hline Value & Mortality & Conversion & Recurrence & $\begin{array}{l}\text { Perforation/ } \\
\text { leak/Fistula }\end{array}$ & $\begin{array}{l}\text { Mesh } \\
\text { infection }\end{array}$ & Reoperation \\
\hline $\begin{array}{l}\text { Rough } \\
\text { mean } \dagger(\%)\end{array}$ & 0.14 & 3.33 & 3.61 & 2.05 & 0.78 & 3.14 \\
\hline $\begin{array}{l}\text { Total } \\
\text { procedures }\end{array}$ & 5,566 & 5,624 & 5,411 & 5,797 & 5,797 & 5,163 \\
\hline Total events & 8 & 180 & 203 & 119 & 45 & 162 \\
\hline
\end{tabular}

${ }^{\dagger}$ The rough mean is the total number of events divided by the total number of procedures (data on all outcomes were not available in all of the manuscripts)

with open repair in patients with ventral hernia. They selected 10 randomized controlled studies which compared the two techniques with a total number of 880 patients. The recurrence rate was not different between laparoscopic and open surgery. The risk of intraoperative enterotomy was slightly higher in laparoscopic hernia repair. The most clear and consistent result was that laparoscopic surgery reduced the risk of wound infection. Laparoscopic surgery shortened hospital stay significantly in 6 out of 9 trials. Laparoscopic repair apparently led to much higher inhospital costs. They concluded that the short-term results of laparoscopic repair in ventral hernia are promising. In spite of the risks of adhesiolysis, the technique is safe but long-term follow-up is needed in order to elucidate whether laparoscopic repair of ventral hernia is efficacious.

Laparoscopic repair of ventral hernia can essentially be extended to any patient who is a candidate for open repair and with an acceptable risk for general anesthesia. ${ }^{29}$ As experience increases, laparoscopic repair of ventral hernia can be safely extended to patients with multiple prior abdominal procedures and large hernias. ${ }^{30}$ Incarceration 
is not a contraindication as onset of anesthesia, muscle relaxation and introduction of pneumoperitoneum make reduction easy.

\section{Conclusion:}

Compared to open repair, laparoscopic repair is technically feasible, safe and effective, with good clinical outcome. It is associated with longer time for surgery but reduced post-operative pain, analgesic requirement, complication rate and infection rate and earlier return to normal activities.

\section{Reference}

1- Salameh JR: Primary and unusual abdominal wall hernia. Surg Clin N Am 2008; 88(1): 45-60.

2- Adotey J.M. Incisional hernia: A review. Niger J Med 2006; 15(1): 34-43.

3- Lomanto D., Iyer S.G., Shabbir A, Cheah WK: Laparoscopic versus open ventral hernia mesh repair; a prospective study, Surg Endosc 2006; 20(7):1030-1035.

4- Courtney CA, Lee AC, Wilson C, O’Dwyer PJ: Ventral hernia repair: A study of current practice. Hernia 2003; 7: 44-46.

5- Fischer, Josef E: Laparoscopic ventral hernia repair. Mastery of Surgery, $5^{\text {th }}$ Edition, 2007; Vol IV: 159-163, editor Lippincott Williams \& Wilkins.

6- Gray SH, Hawn MT, Itani Kamal MF: Surgical progress in Inguinal and ventral incision hernia repair. Surg Clin N Am 2008; 88: 17-26.

7- Rooh-ul-Muqim, Qutb-E-Alam J, Mohammad Z, Muhammad TK, Javeria I, Iftikhar MK, Mehmud A, Aziz W: Laparoscopic Repair of Ventral Hernia an Early Experience at Khyber Teaching Hospital, Peshawar. World J Lap Surg 2008; 1(3): 35-38.

8- Heniford BT, Ramshaw BJ: Laparoscopic ventral hernia repair: A report of 100 consecutive cases. Surg Endosc 2000; 14 : 419-423.

9- White TJ, Santos MC, Thompson JS: Factors affecting wound complications in repair of ventral hernias. Am Surg 1998; 64:276-280.

10- Schumpelick V, Conze J, Klinge U: Preperitoneal mesh repair of incisional hernias: A comparative retrospective study. Chirurgie 1996; 67: 1028-1035.

11- Stoppa RE: The treatment of complicated groin and incisional hernias. World J Surg 1989; 13: 545-554.

12- Rives J, Pire JC, Flament JB, Palot JP, Body C: Treatment of large eventrations. New therapeutic indications apropos of 322 cases. Chirurgie 1985; 111: 215-225.

13- Wantz GE: Incisional hernioplasty with Mersilene. Surg Gynecol Obstet 1991; 172: 129-137.

14- Carlson MA, Frantzides CT, Shostrom VK, Laguna LE: Minimally invasive ventral herniorrhaphy: An analysis of 6,266 published cases . Hernia 2008; 12: 9-22.

15- Toy FK, Bailey RW, Carey S, Chappuis CW, Gagner M, Josephs LG, et al: Multicenter prospective study of laparoscopic ventral hernioplasty: preliminary results. Surg Endosc 1998; 12: 955-959.

16- Wantz GE: Incisional hernioplasty with Mersilene. Surg Gynecol Obstet 1991; 172: 129-137.

17- Shankaran V, Weber DJ, Reed RL, Luchette FA: A review of available prosthetics for ventral hernia repair. Ann Surg 2011; 253(1): $16-26$.

18- van der Linden FT, van Vroonhoven T.J: Long term results after surgical correction of incisional hernia. Neth J Surg 1988; 40: 127-129.

19- Soler N, Verhaeghe P, Essomba A: Treatment of postoperative incisional hernias by composite prosthesis (polyester-polyglactin 910). Clinical and experimental study. Ann Chir 1993; 47: 598-608.

20- Park AE, Birch DW, LovricsP: Laparoscopic and open incisional hernia repair: A comparison study. Surgery 1988; 124: 816-822.

21- Costanza MJ, Heniford BT, Arca MJ, Mayes JT, Gagner M: Laparoscopic repair of recurrent ventral hernias. Am Surg 1998; 64: 1121-1125.

22- Ramshaw BJ, Esartia P, Schwab J, Mason EM, Wilson RA, Duncun TD, et al: Comparison of laparoscopic and open ventral herniorrhaphy. Am Surg 1999; 65: 827-832.

23- Holzman MD, Purut CM, Reintgen K, Eubanks S, Pappas TN: Laparoscopic ventral and incisional hernioplasty. Surg Endosc 1997; 11: 32-35.

24- DeMaria EJ, Moss JM, Sugerman HJ: Laparoscopic intraperitoneal polytetrafluoroethylene (PTFE) prosthetic patch repair of ventral hernia. Prospective comparison to open prefascial polypropylene 
meshrepair. Surg Endosc 2000; 14: 326-329.

25- Schoenmaeckers EJ, Raymakers JF, Rakic S: Complications of laparoscopic correction of abdominal wall and incisional hernias. Ned Tijdschr Geneeskd 2010; 154(45): A2390.

26- Mudge M, Huges LE: Incisional hernia a 10-year prospective study of incidence and attitudes. Br J Surg 1985; 72: 70-71.

27- Heniford BT, Park AE, Ramshaw BJ, Voeller G: Laparoscopic ventral and incisional hernia repair in 407 patients. J Am Coll Surg 2000; 190: 645-650.

28- Sauerland S, Walgenbach M, Habermalz B, Seiler CM, Miserez M: Laparoscopic versus open surgical techniques for ventral or incisional hernia repair. Cochrane Database Syst Rev. Mar 2011; 16; 3: CD007781.

29- LeBlanc KA: Current considerations in laparoscopic incisional and ventral herniorrhaphy. J Soc Laparoendosc Surg 2000; 4: 131-139.

30- Arteaga-Gonzalez I, Martin-Malagon A, Fernandez EM, Carrillo-Pallares A: Which patients benefit most from laparoscopic ventral hernia repair? A comparative study. Surg Laparosc Endosc Percutan Tech 2010; 20(6): 391-394. 